\title{
Acute optic neuritis: prognosis for development of multiple sclerosis
}

\author{
W. G. BRADLEY AND C. W. M. WHITTY \\ From the Department of Neurology, United Oxford Hospitals
}

The clinical picture of acute optic neuritis-a rapid failure of vision with a scotomatous visual field defect in one or both eyes and paraorbital painmay present in a variety of conditions such as retinal vascular lesions, raised intracranial pressure, toxic metabolic and deficiency diseases, or trauma (Woods and Rowland, 1931; Benedict, 1933; Carroll, 1952; Walsh, 1957; Hierons and Lyle, 1959; Kennedy and Carroll, 1960; McAlpine, Lumsden, and Acheson, 1965; British Medical Journal, 1965; Björkenheim, 1966). In the majority of these the primary diagnosis can be made by appropriate examination and investigations. There remains a group which may be termed idiopathic or cryptogenic optic neuritis, since the condition does not appear to be a symptom of other primary disease. Of these about one-third have sufficient evidence from the history or current findings of more than one neurological lesion to justify the diagnosis of multiple sclerosis (Adie, 1930 and 1932; Marshall, 1950; Carroll, 1952). However, the other two-thirds, the majority of the idiopathic group, present a problem in aetiology and prognosis. It is with reference to this group in particular that the question has arisen of multiple sclerosis as the final cause of optic neuritis, only to be revealed by subsequent events. Thus McAlpine et al. (1965) state that multiple sclerosis is the only common cause of acute optic neuritis. Estimates of the proportion of cases of acute optic neuritis later developing multiple sclerosis vary from $11.5 \%$ (Kurland, Auth, Beebe, Kurtze, Lessell, Nagler, and Nafzger, 1963) to $85 \%$ (Lynn, 1959, adapted by McAlpine, 1964). Many published reports are irrelevant to this problem, since they fail to distinguish between patients with and without signs and symptoms suggestive of multiple sclerosis at the time of the initial attack. McAlpine (1964) commented that published data on the frequency of later development of multiple sclerosis are scarce.

The present paper contributes evidence on this point from a follow-up study of cases seen in the Neurology Service at Oxford between 1946 and 1966. They do not comprise all the cases in the Oxford area, but are considered to represent an unselected group since they were referred both from general practitioners to medical and surgical neurology departments and via the Oxford Eye Hospital. In addition to the proportion developing multiple $\varrho$ sclerosis, the frequency of neurological relapses, the degree of later disability, both visual and general, and $\vec{\circ}$ factors influencing the ultimate prognosis have been studied.

\section{MATERIALS AND METHODS}

The records of a series of 123 patients originally diagnosed as having optic neuritis were analysed in an earlier paper $\overrightarrow{.}$ on the clinical features and time course of the acute. attack (Bradley and Whitty, 1967). In that series 50 of $\vec{\circ}$ the original cases were rejected, 12 of these on the grounds that the visual fields were not charted in ta initial episode, or that the fields, though charted, did not conform to the particular form of scotomatous defeet $\mathbb{D}$ we required for our clinical definition of optic neuritig However, when the other clinical features of these 12 and the subsequent changes in visual acuity were examined. they were found to behave in an exactly similar mannef to the $\mathbf{7 3}$ homogeneous cases. We have therefore included $\infty$ them in our present analysis, making a total of 85 cases. Seventy-six of these were successfully traced (Table I): nine were lost to follow-up. Sixty-three of the former were examined personally and three, not seen personally, were house-bound but were under out-patient supervision in the Department, with an established diagnosis of $\mathbb{Q}$ multiple sclerosis. Information on the remaining $10 \stackrel{2}{\Rightarrow}$ came from family doctors. Three of these had died of

TABLE I

DATA ON THE FOLLOW-UP OF PATIENTS Total

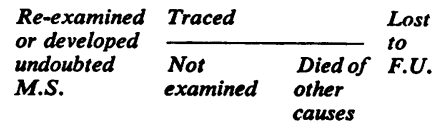

\begin{tabular}{lrrrrr}
\hline $\begin{array}{c}\text { Unilateral optic } \\
\text { neuritis }\end{array}$ & 64 & 48 & 7 & 2 & 7 \\
$\begin{array}{c}\text { Bilateral at } \\
\text { same time }\end{array}$ & 5 & 3 & - & 1 & 1 \\
$\begin{array}{c}\text { Bilateral, less } \\
\text { than 3-month }\end{array}$ & 9 & 9 & - & - & - \\
$\begin{array}{c}\text { interval } \\
\text { Bilateral, more } \\
\text { than 3-month } \\
\text { interval }\end{array}$ & 9 & 6 & - & - & 1 \\
$\begin{array}{c}\text { Totals } \\
\text { T5 }\end{array}$ & 85 & 66 & 7 & 3 & 9
\end{tabular}


other causes (coronary thrombosis, carcinoma of pancreas, riding accident). Information on the remaining seven was considered unreliable, since $33 \%$ of 43 patients personally examined who brought letters from their doctors were found to have neurological signs unknown to the doctors. All these 10 were therefore rejected from further study.

Sixty-six patients form the basis of this paper. During the period of follow-up one patient developed rheumatoid arthritis, one pulmonary sarcoidosis, and one had a para-oesophageal mass which was revealed by chest radiograph at the time of the attack of optic neuritis and which remained the same size at the time of follow-up one year later. Inquiries were made about recurrent attacks of optic neuritis, subsequent neurological symptoms, a history of sinusitis, symptoms suggestive of diabetes mellitus, and the family history. Intercurrent illnesses were also noted. Examination included a full neurological examination with measurement of visual acuity on Jaeger and Snellen charts and the plotting of peripheral and central visual fields. The blood pressure was measured in all and a general examination was performed.

A life chart was then constructed for each patient, with details of each neurological episode plotted on a time scale originating from the first attack of optic neuritis. The minimum number of lesions necessary to explain each symptom and sign in each episode was recorded on this life chart. Where a symptom was accompanied by a sign of the same lesion, only this one lesion was recorded, though the occurrence of both symptoms and signs were noted for the diagnosis of multiple sclerosis. The data from all these charts were then analysed as a whole, and in the sub-groups previously described (Bradley and Whitty, 1967). For purposes of this survey of the late sequelae of optic neuritis, the diagnostic criteria used were largely those of McAlpine et al. (1965).

\section{DEFINITIONS}

Optic neuritis The acute onset of blurred vision in one or both eyes, without demonstrable cause and without pre- or co-existing neurological signs or symptoms other than dizziness.

Definite multiple sclerosis An attack of optic neuritis, later followed by one or more neurological symptoms, relapsing and remitting in character, together with two or more signs (pyramidal and at least one other) of multiple lesions of the central nervous system.

Probable multiple sclerosis An attack of optic neuritis later followed by the development of a sign indicating a separate neurological lesion, without a history of relapsing symptoms.

Devic's disease (neuromyelitis optica) An attack of optic neuritis later followed by rapid transverse myelitis without signs or symptoms of other disseminated lesions.

\section{Mobility grade}

Grade 1. Unrestricted-normal employment or domestic life.

Grade 2. Restricted-able to walk unaided up to $\frac{1}{2}$ mile, and able to use public transport.
Grade 3. Markedly restricted-able to move out of doors with difficulty for up to mile, usually with sticks.

Grade 4. Mobile at home-able to move with difficulty about house with help of furniture; unable to climb stairs.

Grade 5. Immobile at home-chair- or wheel-bound.

Grade 6. Bedridden-permanently.

Neurological lesion A patient who developed at any particular time signs and/or symptoms which could have been caused by one lesion of the central nervous system was deemed to have suffered one 'neurological lesion'. If lesions at three sites in the central nervous system were required to explain the signs and symptoms the patient had suffered three 'neurological lesions'.

Neurological episode A patient who at a particular time developed signs and symptoms of one or more neurological lesions which had not been present before was deemed to have suffered a 'neurological episode' at that particular time.

\section{RESULTS}

SEX AND SIDE INVOLVED The findings in the 66 cases are essentially the same as in the full series of 73 reported elsewhere (Bradley and Whitty, 1967) and indicate that no bias has been introduced by the loss of $22 \%$ of the patients at follow-up. The age structure and distribution of month of onset in the present series were also similar to the full series.

THE FOLLOW-UP PERIOD This ranged from six months to 20 years, the mean being $10 \cdot 2$. Ninety per cent were followed up for four years or more: $33 \%$ for 13 or more years.

NEUROLOGICAL LESIONS EXCLUDING OPTIC NEURITIS One hundred and nine recognized lesions developed in the 66 patients-that is, 1.65 lesions per patient. More important, in view of the different periods of follow-up, is the frequency of lesions per patientyear. Over the whole series, 109 lesions developed in a total of 672 patient-years, an average of 0.18 lesions per patient-year. The distribution is shown in

TABLE II

FREQUENCY DISTRIBUTION OF THE NUMBER OF NEUROLOGICAL LESIONS PER PATIENT-YEAR IN THE WHOLE SERIES

Neurological lesions per patient-year Patients

\begin{tabular}{lcc} 
& No. & $\%$ \\
\hline 0 & 29 & 44 \\
$0.05-0.10$ & 11 & 17 \\
$0.11-0.50$ & 14 & 21 \\
$>0.50$ & 10 & 15 \\
Devic's disease & 2 & 3 \\
Total & 66 & 100
\end{tabular}


Table II. Forty-four per cent of patients suffered no recognized subsequent lesion, $38 \%$ suffered up to 0.5 lesions per year, and $15 \%$ suffered more than 0.5 lesions per year. Three per cent developed a transverse myelitis. There was no significant difference between the sub-groups. The average follow-up period was $9 \cdot 2$ years for those who developed no lesions, which was only slightly less than the period of 10.3 years for those who did develop further neurological lesions.

NEUROLOGICAL EPISODES In Fig. 1 is recorded the proportion of patients at risk developing a neurological episode and a further attack of optic neuritis in either eye at each period after the initial attack of optic neuritis. The episode rate-that is, episodes per patient-was greatest in the first year after the optic neuritis, the frequency decreasing exponentially thereafter. In patients whose progress subsequent to the optic neuritis was observed from six to 20 years it was found that the episode rate during this period was low. Occasional episodes occurred 12 or more years after, but in proportion to the number of patients being observed at that time they were rare when compared with the similar proportion in the first six-year period. The result at 20 years is derived from only five patients and can be discarded. The pattern of recurrence of optic neuritis is similar to that of other neurological episodes. Females continue having neurological episodes for 12 years after optic neuritis, while only one male had a further episode after six years, though the numbers were small in the male group. The length of follow-up was the same for the two sexes.

DIAGNOSIS OF MULTIPLE SCLEROSIS In Fig. 2 we give the number of patients who during the course of follow-up come into the three groups: definite multiple sclerosis (in this we include Devic's disease) $13(20 \%)$; probable multiple sclerosis $21(31 \%)$; and no further neurological disease than optic neuritis $32(49 \%)$. The interval between the initial optic neuritis and the development of signs and symptoms sufficient for the diagnosis of definite multiple sclerosis is plotted, and compared with the group of probable multiple sclerosis and those in whom no diagnosis other than optic neuritis was made. Definite multiple sclerosis had declared itself by four years in all but one case, though patients continued to be observed for up to 20 years in some cases.

The one patient in whom definite multiple sclerosis was diagnosed 18 years after the attack of optic neuritis was a woman of 46 years at the time of attack. At 55 years she had an episode of vertigo and vomiting lasting one week. When seen for this

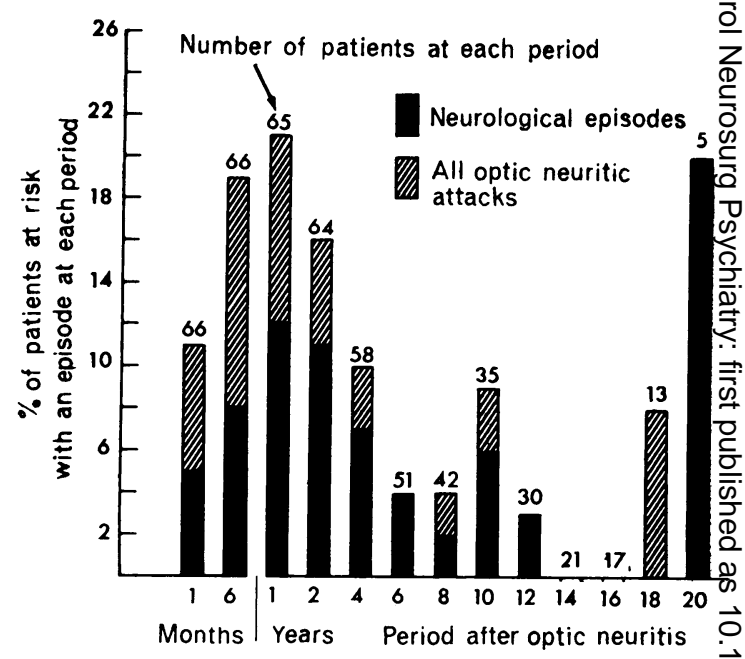

FIG. 1. The percentage of patients at risk suffering $\vec{\omega}$ a symptomatic neurological episode or an attack of optic. neuritis between each period, findings at follow-up examination excluded. Numbers above columns show totato patients at each period.

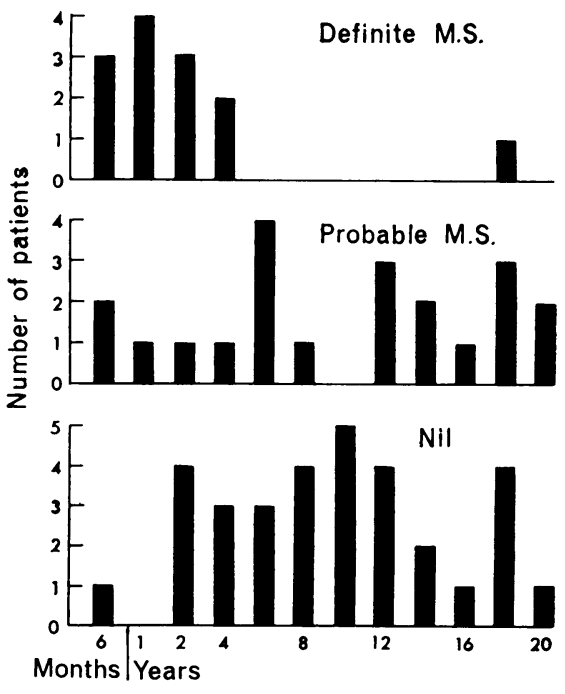

Period after optic neuritis

FIG. 2. The time interval for the development of sufficient symptoms and signs for the diagnosis of 'definite multiple $\mathrm{N}$ sclerosis' (including Devic's disease), 'probable multiple. sclerosis', and the follow-up period of cases with no further N neurological disease. 
survey she was aged 64 years and had minimal nystagmus and a slight right facial weakness, slight ataxia of both arms, and bilateral extensor plantar responses.

The one neurological sign required for the diagnosis of probable multiple sclerosis was most commonly detected at the time of follow-up. There was no difference between the sexes in the time elapsing before the diagnosis of definite or probable multiple sclerosis. The cumulative proportion of patients at risk suffering definite or probable multiple sclerosis at each period after the initial attack of optic neuritis is shown in Figure 3. The proportion with definite multiple sclerosis and Devic's disease reaches a plateau of $20 \%$ in four years after the optic neuritis and shows no significant changes thereafter. The proportion with probable multiple sclerosis rose progressively as more patients came to the follow-up examination.

MOBILITY GRADE FOLLOW-UP Despite the diagnosis of definite multiple sclerosis, including Devic's disease, in 13 cases, and of probable multiple sclerosis in a further 21 , the mobility grade at the time of follow-up examination was remarkably high. All the probable multiple sclerosis cases were in Grade 1 (unrestricted). This applied also to seven of the definite multiple sclerosis; of the remainder of this group one was in each of the Grades 2, 4, 5 , and 6. Both the cases with Devic's disease however were chair- or bed-bound (Grades 5 and 6). Perusal of the case notes showed that of the total of six

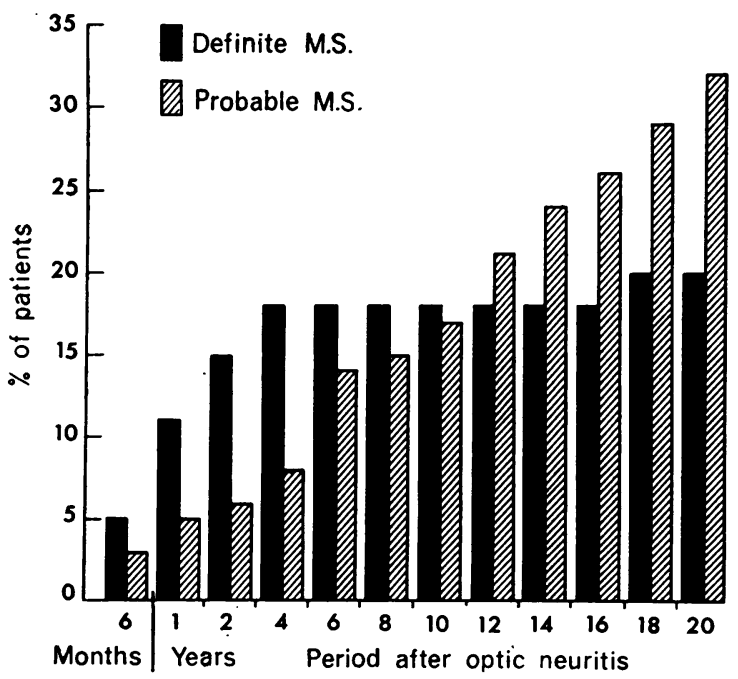

FIG. 3. The cumulative percentage of patients with the diagnosis of 'definite multiple sclerosis' (including Devic's disease), and 'probable multiple sclerosis' at each time interval after optic neuritis. patients who became severely disabled, all had reached that state by four years after the initial attack of optic neuritis.

It will be recalled that of the 85 cases who initially formed the basis of this study (Table I) only three had died, all of unrelated conditions. Thus this favourable prognosis was not due to death of the most affected patients. There is no reason to suppose that patients lost to follow-up were different from those traced, but even if they were all bedridden this would still only increase the proportion in Grade 6 to $13 \%$.

RECURRENT OPTIC NEURITIS Recurrent attacks of optic neuritis occurred in the initially affected eye in 12 patients. Simultaneous bilateral cases and later attacks involving the second eye have been excluded. Thus a recurrent attack occurred in $19 \%$, and of these $74 \%$ suffered only one recurrence.

VISUAL ACUITY AT FOLLOW-UP Eighty-six per cent of patients had $6 / 6$ or $6 / 9$ vision in the eye which had suffered the attack of optic neuritis, and in only $6 \%$ was it as bad as $6 / 36$. There was a slight tendency for the acuity to be worse where recurrent attacks of optic neuritis had occurred, but this tendency was not statistically significant.

FACTORS IN LONG-TERM PROGNOSIS IN PATIENTS WITH OPTIC NEURITIS The data on the 66 patients in this study were analysed to reveal factors bearing on their long-term prognosis. The neurological lesion rate, the diagnosis of multiple sclerosis, the mobility grade, and the rate of recurrent optic neuritis were sub-divided according to sex, age, side of attack, pain with attack, fundal appearances in attack, sinus radiograph abnormalities, month of attack, visual acuity at its worst, and time for vision to return to normal. The analyses were further sub-divided according to whether the initial attack was unilateral or bilateral and according to the time interval in bilateral attacks. No clear differences were detected between unilateral and bilateral sub-groups, but the numbers were too small in the latter to reveal minor variations.

Sex Males developed slightly less neurological lesions per patient-year than females, though this difference was not statistically significant. The frequency with which definite or probably multiple sclerosis was diagnosed was similar in the two sexes.

Age There was a tendency for all indices to become slightly worse with increasing age at the time of the optic neuritis (Table III), that for the lesion-rate being statistically significant at the $5 \%$ level by the method of correlation analysis. The diagnosis of multiple sclerosis was made more 


\section{TABLE III}

EFFECT OF AGE AT THE TIME OF THE OPTIC NEURITIS ON THE DEVELOPMENT OF NEUROLOGICAL DISEASE IN WHOLE SERIES

\begin{tabular}{|c|c|c|c|c|c|c|}
\hline \multirow[t]{3}{*}{$\begin{array}{l}\text { Age } \\
(y r)\end{array}$} & \multicolumn{3}{|c|}{ Diagnosis of M.S. } & \multirow[t]{3}{*}{$\begin{array}{l}\text { Lesions per } \\
\text { patient-year }\end{array}$} & \multicolumn{2}{|c|}{$\begin{array}{l}\text { Mobility } \\
\text { grade }\end{array}$} \\
\hline & 'Definite' & 'Probable' & Nil & & 1 & $2+$ \\
\hline & $\%$ & $\%$ & $\%$ & & $\%$ & $\%$ \\
\hline $0-10$ & $100^{1}$ & - & - & 3.33 & 100 & - \\
\hline $11-20$ & - & 60 & 40 & 0.60 & 100 & - \\
\hline $21-30$ & 18 & 18 & 64 & 1.56 & 100 & - \\
\hline $31-40$ & 20 & 26 & 54 & 1.61 & 90 & 10 \\
\hline $41-50$ & 20 & 35 & 45 & 1.75 & 85 & 15 \\
\hline $51-60$ & 25 & 75 & - & 2.08 & 75 & 25 \\
\hline
\end{tabular}

${ }^{2}$ Only one case.

often, the lesion rate per patient-year increased, and the mobility grade worsened with increasing age.

Side Patients whose initial attack of optic neuritis involved the right eye, though less frequent in numbers, developed more neurological lesions per patient-year (0.23 compared with $0 \cdot 11)$, and this difference was statistically significant at the $1 \%$ level. A similar though not statistically significant trend was noted for the right eye to indicate a poorer prognosis for the diagnosis of multiple sclerosis, and for the recurrence rate of optic neuritis.

Fundal appearances in initial attack of optic neuritis The presence or absence of papilloedema bore no prognostic significance for later neurological disease.

Sinus radiographic abnormalities Patients in whom radiographs of the paranasal air sinuses showed abnormalities developed fewer neurological lesions per patient-year (0.08) than those with normal sinuses $(0 \cdot 23)$. The difference was statistically significant at the $1 \%$ level. A similar, though not statistically significant trend was noted for the development of multiple sclerosis.

Pain with optic neuritis Patients whose optic neuritis was painful were more likely to develop further neurological lesions ( $0 \cdot 19$ lesions per patientyear) than those without pain $(0 \cdot 12)$, this result being statistically significant at the $5 \%$ level. A similar but not significant result was found for the diagnosis of multiple sclerosis.

Recurrent optic neuritis As might be expected, patients who developed recurrent attacks of optic neuritis also developed more neurological lesions per patient-year. This was significant at the $0.1 \%$ level. A similar though not statistically significant trend was noted for the development of definite multiple sclerosis.

Visual acuity and month of onset These showed no prognostic significance for further lesions.
Atypical scotomata Six cases had scotomata during the attack of optic neuritis which were atypical $Z$ in being other than central, centrocaecal, or para- $\stackrel{\mathbb{D}}{\leftarrow}$ central-most being quadrantic defects and allo occurring in the unilateral sub-group. The incidence of the diagnosis of multiple sclerosis and the neurological lesion rate were lower in these, though differences were not statistically significant.

Cerebrospinal fluid at initial attack of optic neuritis The cerebrospinal fluid was examined in only $15 ₹$ of the cases at the time of the initial attack and was $\Rightarrow$ abnormal in only four. The gamma-globulin level $\stackrel{\oplus}{\stackrel{(}{+}}$ was measured in recent cases only and will not be? discussed. The frequency of late neurological disease was similar in those with normal and $\frac{\bar{\Phi}}{\square}$ abnormal cerebrospinal fluid.

DISCUSSION

The clinical diagnosis of multiple sclerosis is always $\overrightarrow{\vec{\omega}}$ to some extent tentative; and in cases where it has $\stackrel{\circ}{\circ}$ been confidently presumed for many years it may finally prove to be wrong (Matthews, 1962). At present the necropsy examination is the only certain $\stackrel{\omega}{-}$ diagnostic arbiter. Recent work on the gamma globulin fraction of the cerebrospinal fluid protew $\overrightarrow{0}$ (Foster and Horn, 1962; Prineas, Teasdale, Latne and Miller, 1966) shows that this may help to distinguish established multiple sclerosis from other neurological diseases. It remains to be seen whether $\frac{D}{2}$ the gamma-globulin level at the time of the initian attack of optic neuritis will forecast the developme of multiple sclerosis. Gamma-globulin levels we not available in this study and the cell count, total $\infty$ protein, and Lange curves of cerebrospinal fluid were unhelpful.

McAlpine et al. (1965) suggested that the diagnosis of multiple sclerosis should be made in patients with an attack of acute optic neuritis followed by $\frac{2}{\varnothing}$ one or more neurological relapses and presence of $\varrho$ neurological signs of two or more lesions of the $\overrightarrow{\overrightarrow{0}}$ central nervous system. However, the numerical 3 approach cannot supersede clinical assessment, lest a patient with a past history of an attack of optic? neuritis who suffers bilateral strokes be said to be suffering from multiple sclerosis. The diagnosis of $\overline{0}$ definite multiple sclerosis was made in 13 cases $(20 \%)$ 음 on McAlpine's criteria and in all the case histories substantiated the diagnosis. However, these criteria 8 have been regarded as too lax, especially for use in $₹$ therapeutic trials (Schumacher, Beebe, Kibler, ㅇ Kurland, Kurtzke, McDowell, Nagler, Sibley, Tourtellotte, and Willmon, 1965). The label 'prob- o able multiple sclerosis' is a far less certain one. For this, the requirements of McAlpine et al. (1965), if $O$ accepted mechanically, could include in this category $N$ 
patients with cervical myelopathy, a stroke, and many other conditions - and even a careful history might not always exclude them. This diagnosis was applied to $21(31 \%)$ of the cases in this series, though a sceptical neurologist might have made the diagnosis in fewer.

The total number of neurological lesions deduced from the patient's signs and symptoms offers a quantitative approach which is well suited to the present type of study. A similar attempt to quantify severity and progress of multiple sclerosis was developed by Alexander (Alexander, 1951; Alexander, Berkeley, and Alexander, 1958) and its value cogently argued. We have made no attempt to weight signs in preference to symptoms, though this might improve the method. The present study shows that $44 \%$ of those who suffer an attack of optic neuritis will develop no other neurological lesion in the next 10 years, and that over the whole series only $0 \cdot 18$ lesions develop per patient-year.

This relatively benign prognosis is worthy of emphasis. It compares favourably with previous reports of the annual relapse rate (a term based on 'neurological episodes' rather than 'lesions' as defined above) of 0.27 to 1.15 (Müller, 1949; McAlpine and Compston, 1952; Thygesen, 1953; Alexander et al., 1958) in patients with multiple sclerosis.

The present study shows that most symptomatic neurological episodes (Fig. 1) occur in the first six years after the attack of optic neuritis. Similarly, if 'definite multiple sclerosis' were going to develop in a patient during the period of the study, it usually did so in the first four years. The interval between the optic neuritis and the transverse myelitis in the two cases of Devic's disease was six months and four years, respectively. Collis (1965) found that all of his patients who were going to develop multiple sclerosis had shown their first symptom within four years, though he does not record at what time the definite diagnosis was made. Taub and Rucker (1954) found that in more than half of the cases with multiple sclerosis the onset fell within the first five years, and since 'onset' was taken as the time when the patient was seen with the symptoms and not the time of their development (Collis, 1965), the real interval may be shorter.

Despite these findings, there are many cases recorded in the literature with long intervals between an attack of optic neuritis and subsequent symptoms of multiple sclerosis. Adie (1932) recorded a case with an interval of 24 years, and found the average interval 6.8 years. Even longer intervals of 29 years (Lynn, 1959) and 37 years (McAlpine and Compston, 1952) have been recorded. The average interval quoted by other authors ranges from 3.6 years to eight years (Yaskin, Spaeth, and Vernlund, 1951; Wybar, 1952; Leibowitz, Alter, and Halpern, 1966). However, Otradovec and Votočková (1962) and Kurland et al. (1963) found that the proportion of patients with multiple sclerosis rises with time after the initial optic neuritis, though the latter found the effect small after 10 years.

Comparison of the results of this study with others in the literature is difficult, not only because the criteria for the diagnosis of multiple sclerosis are frequently not stated, but also because many authors include all cases of acute optic neuritis, with or without other neurological signs, for follow-up. Here, since we attempted a prognostic study, those already having neurological signs and symptoms suggestive of other neurological lesions, at the time of the attack of optic neuritis, have been excluded. Table IV summarizes some of the previous reports on this problem. Reports in Section 1 may be compared with the present study. Estimates of the frequency of development of multiple sclerosis range from $11.5 \%$ in the study of Kurland et al. (1963) to $85 \%$ from Lynn's (1959) figures adapted by McAlpine (1964). Kurland et al. (1963) studied young male servicemen followed for 12 to 15 years and required agreement between a panel of neurologists for acceptance of the diagnosis of multiple sclerosis. McAlpine (1964) selected patients examined by Lynn (1959) after periods of from five to 29 years after the initial optic neuritis. It is difficult to explain such widely different estimates except by postulating a difference of diagnostic criteria. Another difficulty in comparison of such studies rests on the different lengths of follow-up of patients. A life table type of presentation provides information which is more easily compared.

However, for the clinician who has to deal with the individual case the need is to know what the chances are, on the simple data available, of one particular patient subsequently developing multiple sclerosis. Males developed this less frequently in Collis's (1965) series, and a similar result was obtained in the neurological lesion-rate in the present study, though in neither series was the difference statistically significant. Collis (1965) found that all his patients under the age of 20 at the time of the optic neuritis developed multiple sclerosis, while Taub and Rucker (1954) found only 14\% (Collis incorrectly stated $6 \%$ ). Both authors agree that it is unlikely to develop in cases who suffer optic neuritis after the age of 45 . Kennedy and Carroll (1960) found $27 \%$ of a group of children under 16 years with optic neuritis developed multiple sclerosis, while Hierons and Lyle (1959) found $8 \%$ in a group of children under 13 years with bilateral attacks. The present study included only six patients under 20 
years at the time of the optic neuritis (Table III): one developed sufficient neurological episodes for the diagnosis of 'Definite Multiple Sclerosis' and three others fell into the group of 'probable multiple sclerosis'. Above this age, there was a tendency for the proportion with 'definite multiple sclerosis' and for the neurological lesion-rate to rise with age; and this continued into the sixth decade. Advanced age seemed to offer no protection.

Kurland et al. (1963) tried to correlate a large number of factors in the initial optic neuritis with subsequent development of multiple sclerosis in a group of entrants to the U.S. Armed Forces. However, most of them proved negative. Of the total of $\mathbf{4 3}$ factors, only four showed a positive correlation, and, as they note, this number might be expected as a chance finding. Since the four factors were unequal pupils, absence of field defect, poorer than average vision, and higher than average intelligence, chance is perhaps the most likely explanation.

Pain with the initial optic neuritis had no bearing on later multiple sclerosis both in Collis's (1965) series, and in the present study. Similarly the fundal appearances in the attack, visual acuity, month of onset, and cerebrospinal fluid changes were all of no prognostic significance in the present study. Interestingly, Leibowitz et al. (1966) found that, in Israel, European Jews are six times more likely to develop multiple sclerosis following optic neuritis than those from Afro-Asia.

In the present study, patients whose initial optic neuritis affected the right eye were more likely to develop the further neurological lesions of multiple ${ }^{\circ}$ sclerosis. Bradley and Whitty (1967) also found into acute optic neuritis that the right eye was affected less frequently than the left. Both findings remain unexplained. Radiographic evidence of sinusitis at the time of the optic neuritis conveyed a bettero prognosis for the later development of multiples sclerosis. This might suggest that some attacks of optic neuritis are precipitated by paranasal sinusitis and may form an aetiological category which can be separated from the general group with its proportion of multiple sclerosis. Similarly, patients with scotomata other than the typical central varietyo tended to develop less multiple sclerosis in late years, and this might suggest that some were due to lesions other than optic neuritis, such as retina? branch artery occlusion. We included these in thes present series because all the other clinical features $\overrightarrow{0}$ of the immediate attack were similar to the maingroup, as was the course of the actual optic neuritis. However, the differences shown in this follow-up?study lend some support to the argument that the type of field defect should form part of the originatu diagnosis.

The relatively benign overall prognosis revealet in the present study is worth emphasis. At \&n? average of 10 years after the attack of optic neuripis$91 \%$ of patients were completely unrestricted ${ }^{\mathrm{a}} \mathrm{n}_{\overline{-}}$ their activities. Even in those with 'definite multieed sclerosis', $64 \%$ were unrestricted. This is far bettere than might be expected in multiple sclerosis ging general (Müller, 1949; Lazarte, 1950). Bauer agd Firnhaber (1965) found only about a third of patiems

\begin{tabular}{|c|c|c|c|c|c|c|c|c|c|}
\hline Author & Date & $\begin{array}{l}\text { Follow-up } \\
\text { Period }(y r)\end{array}$ & Details & $\begin{array}{l}\text { TABLE } \\
\text { Def. M.S. } \\
(\%)\end{array}$ & $\begin{array}{l}\text { IV } \\
\text { Prob. M.S. } \\
(\%)\end{array}$ & $\begin{array}{l}\text { Devic's } \\
\text { Disease } \\
(\%)\end{array}$ & $\begin{array}{l}\text { Leber's } \\
\text { Disease } \\
(\%)\end{array}$ & $\begin{array}{l}\text { Diabetes } \\
(\%)\end{array}$ & $\begin{array}{l}\text { Nil } \\
(\%)\end{array}$ \\
\hline \multicolumn{10}{|c|}{ I. Excluding those with neurological signs and symptoms at initial attack of optic neuritis } \\
\hline Taub and Rucker & 1954 & $10-15$ & - & 32 & - & - & - & - & 68 \\
\hline \multirow[t]{2}{*}{ Hierons and Lyle } & 1959 & 6 & $\begin{array}{l}\text { Bilateral } \\
\text { adults }\end{array}$ & 24 & - & - & - & - & 76 \\
\hline & & 4 & $\begin{array}{l}\text { Bilateral } \\
\text { children }\end{array}$ & 8 & - & - & 一 & 一 & 92 \\
\hline $\begin{array}{l}\text { Lynn } \\
\text { Lynn (adapted by }\end{array}$ & 1959 & $6 / 12-29$ & - & 50 & - & - & - & 一 & 50 \\
\hline McAlpine) & 1964 & $5-29$ & - & 85 & - & - & - & - & 15 \\
\hline Kennedy and Carroll & 1960 & 8 & Children & 27 & - & - & - & - & 73 \\
\hline Kurland et al. & 1963 & $12-15$ & Males & $11 \cdot 5$ & $1 \cdot 5$ & - & - & - & 87 \\
\hline Collis & 1965 & $7-20$ & - & 36 & - & - & - & 3 & 61 \\
\hline Present series & 1968 & $6 / 12-20$ & - & 17 & 31 & 3 & - & - & 49 \\
\hline \multicolumn{10}{|c|}{ II. Including those with neurological signs and symptoms at initial attack of optic neuritis } \\
\hline Marshall & 1950 & $5-20$ & - & 36 & - & - & - & - & - \\
\hline Kinnier Wilson & 1954 & $?$ & $\begin{array}{l}\text { From } \\
\text { literature }\end{array}$ & 65 & - & - & 一 & - & 35 \\
\hline Hyllested and Moller & 1961 & $2-15$ & - & 13 & 25 & - & 13 & - & 49 \\
\hline \multicolumn{10}{|c|}{ III. Only considering neurological signs at initial attack of optic neuritis } \\
\hline Adie & 1930 & $?$ & - & 34 & 33 & - & - & - & 33 \\
\hline Adie & 1932 & $?$ & - & 31 & 42 & - & - & - & 27 \\
\hline Marshall & 1950 & 0 & - & $13 \cdot 5$ & 17 & - & - & - & $69 \cdot 5$ \\
\hline Carroll & 1952 & $\mathbf{0}$ & - & 32 & 16 & 4 & - & - & 48 \\
\hline
\end{tabular}


with multiple sclerosis in the unrestricted category after 10 years. Our results agree with McAlpine's (1961) findings in 241 patients with multiple sclerosis followed for more than 10 years, that $57 \%$ of those whose first symptom was optic neuritis were unrestricted, while only $27 \%$ of those who had some other presentation were in that category. $\mathrm{He}$ suggests that there is a benign form of multiple sclerosis which is commoner in those presenting with acute optic neuritis. Our study would support such a view.

\section{SUMMARY}

Cases of acute optic neuritis, with no other pre- or co-existing neurological signs, seen in the Department of Neurology at Oxford from 1946 to 1966 are reviewed to determine the proportion who subsequently developed multiple sclerosis and the prognostic factors for this. Eighty-five cases complied with stated criteria for the diagnosis of optic neuritis. Sixty-six of these were available for follow-up: 63 were examined personally: three others were attending the Department regularly with undoubted multiple sclerosis. Three of the total had died of other causes. The follow-up period ranged from six months to 20 years with a mean of $10 \cdot 2$ years.

By stated criteria, $13(20 \%)$ were diagnosed as having definite multiple sclerosis, and $21(31 \%)$ as probable multiple sclerosis. Thirty-two $(49 \%)$ had not developed subsequent neurological disease. Reasons are given for scepticism about the diagnosis of probable multiple sclerosis. The diagnosis of subsequent discrete neurological lesions was made from signs and symptoms in each episode; and 109 such lesions were found in 66 patients, a rate of $0 \cdot 18$ lesions per patient-year.

With regard to prognosis, patients with left-sided attacks, younger patients, those with painless attacks, and those with abnormal sinus radiographs at the time of attack developed neurological lesions statistically less frequently. There was a tendency for females, and those with typical rather than atypical scotomata (as defined), to do worse, though this was not statistically significant. Presence or absence of papilloedema, degree of loss of visual acuity, and month of onset were not significant prognostically. Symptomatic neurological episodes and attacks of recurrent optic neuritis became less frequent as time passed after the initial optic neuritis. As for the degree of disability, $60(91 \%)$ were unrestricted in their activities at the end of the follow-up, two $(3 \%)$ bedridden, and a further four (5\%) housebound. Of the patients with definite multiple sclerosis $64 \%$ were unrestricted and $27 \%$ house- or bed-bound.
These findings are discussed and compared with previous reports. The relatively favourable prognosis for patients with acute optic neuritis as the onset of multiple sclerosis is emphasized.

The authors wish to thank Professor Ritchie Russell and Dr. J. M. K. Spalding for allowing them to study patients under their care; Dr. D. J. Newell, Reader in Biostatistics in the University of Newcastle upon Tyne, for statistical help and for reading the manuscript; the Medical Illustration Department of the University of Newcastle upon Tyne for preparation of figures; and Miss Jenny Aspden for her meticulous tracing of patients for follow-up.

\section{REFERENCES}

Adie, W. J. (1930). Acute retrobulbar neuritis in disseminated sclerosis. Trans. ophthal. Soc. U.K., 50, 262-266.

(1932). Aetiology and symptomatology of disseminated sclerosis. Brit. med. J., 2, 997-1000.

Alexander, L. (1951). New concept of critical steps in course of chronic debilitating neurologic disease in evaluation of therapeutic response. Arch. Neurol. Psychiat. (Chic.), 66, 253-271.

—, Berkeley, A. W., and Alexander, A. M. (1958). Prognosis and treatment of multiple sclerosis-quantitative nosometric study. J. Amer. med. Ass., 166, 1943-1949.

Bauer, H. J., and Firnhaber, W. (1965). Prognostic criteria in multiple sclerosis. Ann. N.Y. Acad. Sci., 122, 542-551.

Benedict, W. L. (1933). Retrobulbar neuritis and disease of the nasal accessory sinuses. Arch. Ophthal., 9, 893-906.

Björkenheim, B. (1966). Optic neuropathy caused by vitamin-B deficiency in carriers of the fish tapeworm, Diphyllothrium latum. Lancet, 1, 688-690.

Bradley, W. G., and Whitty, C. W. M. (1967). J. Neurol. Neurosurg. Psychiat., 30, 531-538.

British Medical Journal (1965). Retrobulbar neuritis from monoamineoxidase inhibitors. 2, 606.

Carroll, F. D. (1952). Optic neuritis: a 15-year study. Amer. J. Ophthal., 35, 75-82.

Collis, W. J. (1965). Acute unilateral retrobulbar neuritis. Arch. Neurol (Chic.), 13, 409-412.

David, H. A., and Newell, D. J. (1965). The identification of annual peak periods for a disease. Biometrics, 21, 645-650.

Foster, J. B., and Horn, D. B. (1962). Multiple sclerosis and spinalfluid gamma-globulin. Brit. med. J., 1, 1527-1528.

Hierons, R., and Lyle, T. K. (1959). Bilateral retrobulbar optic neuritis. Brain, 82, 56-67.

Hyllested, K., and Møller, P. M. (1961). Follow-up on patients with a history of optic neuritis. Acta ophthal. (Kbh.), 39, 655-662.

Kennedy, C., and Carroll, F. D. (1960). Optic neuritis in children. Arch. Ophthal., 63, 747-755.

Kinnier Wilson, S. A. (1954). Neurology, 2nd ed., edited. A. N. Bruce, Butterworth, London.

Kurland, L. T., Auth., T. L., Beebe, G. W., Kurtze, J. F., Lessell, S., Nagler, B., and Nafzger, M. D. (1963). Studies in the natural history of multiple sclerosis. Trans. Amer. neurol. Ass., 88, 231-232, and 233-235.

Lazarte, J. A. (1950). Multiple sclerosis:prognosis for ambulatory and non-ambulatory patients. Ass. Res. nerv. Dis. Proc., 28, $512-523$.

Leibowitz, U., Alter, M., and Halpern, L. (1966). Clinical studies of multiple sclerosis in Israel. Arch. Neurol. (Chic.), 14, 459-466.

Lynn, B. H. (1959). Retrobulbar neuritis. A survey of the present condition of cases occurring over the last 56 years. Trans. ophthal. Soc. U.K., 79, 701-716.

McAlpine, D. (1961). The benign form of multiple sclerosis. Brain, 84, 186-203

- (1964). The benign form of multiple sclerosis : results of a longterm study. Brit. med. J., 2, 1029-1032.

, and Compston, N. (1952). Some aspects of the natural history of disseminated sclerosis. Quart. J. Med., 21, 135-167.

Lumsden, C. E., and Acheson, E. D. (1965). Multiple Sclerosis. A Reappraisal. Livingstone, Edinburgh and London. 
Marshall, D. (1950). Ocular manifestations of multiple sclerosis and relationship to retrobulbar neuritis. Trans. Amer. ophthal. Soc., 48, 487-525.

Matthews, W. B. (1962). Epilepsy and disseminated sclerosis. Quart. J. Med., 31, 141-155.

Müller, R. (1949). Studies on disseminated sclerosis. Acta med. scand., suppl. 222.

Otradovec, J., and Votosková, J. (1962). Etiologie akutnich neuritiol optiku Sborn lék, 64, 234. Quoted by McAlpine et al. (1965). Mult. Sclerosis Abstr., 7, 264.

Prineas, J., Teasdale, G., Latner, A. L., and Miller, H. (1966). Spinalfluid gamma-globulin and multiple sclerosis. Brit. med. J., 2, 922-924.

Schumacher, G. A., Beebe, G., Kibler, R. F., Kurland, L. T., Kurtzke, J. F., McDowell, F., Nagler, B., Sibley, W. A., Tourtellotte, W. W., and Willmon, T. L. (1965). Problems in experimental trials of therapy in multiple sclerosis. Ann. N.Y. Acad.Sci., 122, 552-568.
Taub, R. G., and Rucker, C. W. (1954). The relationship of retro-으 bulbar neuritis to multiple sclerosis. Amer. J. Ophthal., 37, Z 494-497.

Thygesen, P. (1953). The Course of Disseminated Sclerosis. Rosenkilde and Bagger, Copenhagen.

Walsh, F. B. (1957). Clinical Neuro-Ophthalmology, 2nd ed. Baillière Tindall and Cox, London.

Wilson, S. A. K. (1954). Neurology, 2nd ed., edited by A. N. Bruce. T) Butterworth, London.

Woods, A. C., and Rowland, W. M. (1931). An etiologic study of a $\stackrel{\bigcirc}{\supset}$ series of optic neuropathies. J. Amer. med. Ass., 97, 375-379.

Wybar, K. C. (1952). The ocular manifestations of disseminated sclerosis. Proc. roy. Soc. Med., 45, 315-319.

Yaskin, J. C., Spaeth, E. B., and Vernlund, R. J. (1951). Ocular manifestations of 100 consecutive cases of multiple sclerosis Amer. J. Ophthal., 34, 687-697. 